\title{
O RELÓGIO, O CINEMATÓGRAFO E O INSTANTE: HENRI BERGSON NA VIRADA DO SÉCULO
}

\section{YVES SÃO PAULO ${ }^{1}$}

RESUMO: O relógio e o cinematógrafo são duas invenções populares do século XIX. As duas compartilham uma característica em comum: o tratamento do tempo como sendo quantitativo. Henri Bergson traça o paralelo entre o cinematógrafo e a inteligência. $\mathrm{O}$ cinematógrafo refaz o movimento a partir de instantes. Mas o tempo é mais que uma coleção de instantes. O cinematógrafo e o relógio tratam o devir sempre do mesmo modo. Com o auxílio de Mary Ann Doane, daremos uma segunda chance ao cinematógrafo. Esta máquina criada ao apagar das luzes do século XIX é capaz de fazer arte. E assim, ela também é capaz de criar uma experiência de duração.

PALAVRAS-CHAVE: Henri Bergson, Mary Ann Doane, Cinema, Tempo, Duração.

ABSTRACT: The clock and the cinematograph are two of the most popular inventions of the XIXth century. Both of them share a common characteristic: the treatment of time as quantitative. Henri Bergson draws the parallel between the cinematograph and the intelligence. The cinematograph recreates the movement from the connection of instants. But time is more than just a collection of instants. The cinematograph and the clock treat what is to become always of the same way. With the assistance of Mary Ann Doane, we will give a second chance to the cinematograph. This machine created at the turning off the lights of the nineteenth century is capable of making art. And therefore, it is also capable of creating an experience of duration.

Keywords: Henri Bergson, Mary Ann Doane, Cinema, Time, Duration.

\section{Introdução}

O tratamento dado ao tempo observado enquanto extensão e quantidade pode ser retraçado até os antigos como a filosofia de Zenão, por exemplo. O que encontramos na modernidade é ampliação deste tratamento e o aumento de sua importância. No século XIX diferentes máquinas são criadas para a compreensão do tempo partindo do pressuposto que ele possa ser dividido, calculado. $\mathrm{O}$ advento da fotografia instantânea certamente é um primeiro momento. O instante, coisa fugidia, que tão logo nos demos conta já se transformou em

\footnotetext{
${ }^{1}$ Mestrando em Filosofia pela Universidade Federal da Bahia (UFBA)/Bolsista Capes. Editor da Revista Sísifo. E-mail: yvessaopaulo@gmail.com.
} 
memória, inscrevendo-se no reino do passado, pode agora ser tomado em mãos. O instante é registrado, arquivado.

Não tarda para que o uso da fotografia instantânea seja utilizado para a compreensão do movimento. Muybridge e Marey fotografam a sequência do movimento de pessoas caminhando, subindo e descendo escadas, a corrida de um cavalo. Os diversos instantes de uma corrida agora podem ser registrados externamente, e analisados. O movimento constitui a sequência dos pontos ocupados pelo corpo ao longo de sua trajetória. E assim, o século XIX se aproxima da precisão milimétrica que lhe é tão cara. A precisão das máquinas.

A precisão que socialmente passa a ser concedida às pessoas por meio do relógio. Instrumento que rapidamente se difunde entre as populações das nações ocidentais como artigo de moda que lhes ordena um novo estilo de vida. A urbe moderna exige a precisão do cidadão. $\mathrm{O}$ tempo, precisamente dividido no reino do relógio, acelera as relações sociais. $\mathrm{O}$ relógio é o perfeito exemplo do tempo quantitativo, o tempo nunca mutável.

Ao final deste mesmo século uma invenção para coroar todos estes esforços: o cinematógrafo. $\mathrm{O}$ movimento registrado em 16 quadros por segundo e reproduzidos para uma plateia. A vida apressada da urbe moderna era registrada pelas máquinas de filmar que se espalhavam por todos os cantos do globo. E logo não mais era apenas a vida apressada da urbe. As plateias testemunhavam pessoas de civilizações distantes em suas culturas exóticas. Animais nunca antes vistos. Acontecimentos lidos em jornais e que tomavam corpo e movimento.

Mas um filósofo ao princípio do século XX nota que esta máquina das maravilhas, na verdade, repete a mesma ilusão que as outras máquinas. Repete a mesma ilusão que nosso pensamento. O tempo, escreve ele, não é apenas um amontoado de instantes. Não é apenas os diferentes posicionamentos do corpo ao longo de sua trajetória. O tempo é uma experiência. É duração.

Henri Bergson não sabia, mas por meio de sua leitura do cinematógrafo dava início a um dos campos mais persistentes dos estudos de cinema: a analogia filme/mente. Mas passava longe de sua analogia a ideia de ler o cinematógrafo enquanto produtor de arte. Sua preocupação maior estava ao lado do aspecto "mente" da analogia. O que não significa que sua fala a respeito do "filme" esteja equivocada. O cinematógrafo atua por meio de uma ilusão, e mais à frente a descreveremos.

O cinematógrafo visto enquanto arte possui uma característica que o distingue de todas as demais invenções aqui listadas. É a sua competência de reunir o tempo quantitativo e a 
duração. Para nos auxiliar em meio a esta interpretação, visitamos The emergence of cinematic time, de Mary Ann Doane, um estudo sobre a virada do século XIX para o XX, que inclui uma leitura da filosofia de Bergson. Nosso objetivo neste artigo é conhecer melhor a visão sobre o instante, sobre o tempo quantitativo fornecido pelas máquinas, e a competência do cinematógrafo de ir além.

\section{Mecanismo cinematográfico do pensamento}

Em A evolução criadora, Bergson desenvolve uma analogia entre a inteligência e o cinematógrafo que já utilizava há alguns anos em sala de aula. $\mathrm{O}$ cinematógrafo constituía a este momento uma curiosidade popular, um artefato de diversão dificilmente encarado com seriedade. No estudo de Bergson, a invenção dos Lumière adentra o campo do pensamento que tende a ignorar o caráter próprio do tempo e do movimento. $\mathrm{O}$ pensamento habitual tende a tomar o movimento a partir de posições. Tomar o tempo por espaço. E, assim, retirar do movimento a mobilidade.

"O papel da inteligência, com efeito, é o de presidir a ações" (BERGSON, 2005, p. 323), escreve Bergson. Nossa inteligência está voltada para um caráter prático, de atuar no mundo que nos rodeia. Na prática de uma atividade não é todo o esforço que teremos que desempenhar que adentra em nossa imaginação. Não é, também, todo o caminho que teremos que percorrer até a conclusão. Tomamos apenas o ponto final, imóvel; mais que isso, imutável. É preciso, para a ação, que o objetivo não mude enquanto nos deslocamos até ele. O que significa que ao querer pegar um copo d'água, não imaginamos todos os músculos se contraindo, ou todo o percurso do braço, apenas é visualizado o ponto final.

“O espírito transporta-se imediatamente para o objetivo, isto é, para a visão esquemática e simplificada do ato considerado com realizado" (Idem, p. 324). A inteligência possui esta capacidade de imaginar a ação como realizada, mas o faz por meio de uma síntese do movimento a ser realizado. Ou seja, representa ao final do movimento um ponto de repouso. Nossa inteligência salta de um ponto de repouso a outro, antecipando a imagem do movimento realizado. $\mathrm{O}$ intermédio entre estes dois pontos é ignorado. O principal da ação é a conclusão.

Para além de visualizar o objetivo enquanto um ponto imóvel no espaço é preciso que a inteligência também tome o meio em que o ponto final se encontra como imóvel. Não seríamos capazes de dar um termo à nossa ação caso figurássemos o mundo em que o objetivo se encontra como um escoamento. Como se o objetivo pudesse não mais estar lá ao momento 
em que tento alcançá-lo. Assim também a inteligência toma a matéria enquanto uma "constante", algo que não vai se alterar. Isto não significa que não enxergamos as mudanças da matéria. Pelo contrário, as representamos por meio de estados. E é tomando um estado da matéria como certo que promovemos nossos atos. Como se durante nossa ação a matéria permanecesse naquele estado. O caso é que a matéria está numa constante mutação, assim como nós. Mas apenas atestamos algumas destas mudanças, que nos aparecem mais radicalmente. É este o entendimento que temos por aquilo que até aqui chamamos estado, que nos permite antecipar o termo de nossas atividades.

Do devir infinitamente variado da natureza retiramos um devir geral. Os movimentos que se desenvolvem são diferentes. O movimento que leva do amarelo para o verde é diferente daquele que leva do verde para o azul. Na atribuição de estados para os movimentos da matéria, estabelecemos pontos bem delimitados para esta mudança qualitativa. Estes pontos recortam os estados que mais claramente, que mais distintamente, conseguimos atribuir à mudança. Deixamos de lado o devir próprio a esta mudança para atribuir-lhe um devir geral. Conseguimos distinguir os devires entre si ao representá-los por meio de estados, mas substituímos a especificidade da mudança.

É dentro deste sistema que Bergson insere sua colocação a respeito do cinematógrafo. $\mathrm{O}$ aparelho criado pelos irmãos Lumière teria a mesma competência que a inteligência retirando do devir a variabilidade infinita, pondo um devir geral. Um movimento geral. O exemplo dado por Bergson é o registro da passagem de um regimento. O cinematógrafo capta uma série de fotografias instantâneas desta passagem. O movimento, portanto, é reconstituído por meio desta sequência de fotografias. Reconstitui a mobilidade por meio do imóvel. O que faz o cinematógrafo é captar diferentes posições dos corpos móveis ao longo de seu percurso.

É comum à espécie humana que o movimento de individuo para individuo seja variável. Mesmo com a passagem uniforme do regimento, em que cada membro do conjunto busca atuar da mesma maneira que os demais, em um mesmo ritmo, há a variabilidade dos movimentos. Bergson aponta que o cinematógrafo não é capaz de registrar esta variabilidade. Exatamente por tomar diferentes posições ao longo do percurso. Diferentes estados, como colocamos pouco antes. Vemos movimento no filme, mas não movimento pessoal. Um movimento geral, Bergson escreve. "O procedimento, portanto, consistiu em extrair de todos os movimentos próprios a todas as figuras um movimento impessoal, abstrato" (Idem, p.330), numa ação semelhante ao que faz a inteligência, a percepção e a linguagem. Toma do 
movimento apenas alguns momentos, em que se pode enxergar a alteração de um estado para outro.

Nosso conhecimento atua de modo a assumir pontos de vista do que ocorre ao nosso redor. Por meio desta observação externa, podemos apenas apontar diferentes estados. Ignoramos, assim, o devir interno às coisas. "Postamo-nos fora dela para recompor artificialmente seu devir" (Idem, p. 331), construindo um devir abstrato e artificial, buscando imitar o que havia no devir original. Bergson resume sua colocação: "o mecanismo de nosso conhecimento usual é de natureza cinematográfica" (Idem). Trata-se de uma afirmação envolta em controvérsia, especialmente dada a mudança que se daria nas décadas seguintes em torno da recepção do cinema pelos meios intelectuais. O que levou até mesmo um bergsonista como Deleuze a se opor a esta colocação, escrevendo que se trata de um título injusto.

É interessante, para nosso estudo, apontarmos um ponto sobre esta discussão: a ciência costuma pôr-se externamente aos objetos de estudo e assumir pontos de vista. O movimento assim visto pode ser reconstituído por meio da alocação dos instantes. No século XIX, assim se estudava o movimento. Assim se chegou à conclusão que um cavalo em corrida nunca está com todas as quatro patas sem tocar o chão. E a máquina de filmar, neste sentido, foi criada por industriais em França (os irmãos Lumière) e por um inventor afeito pela ciência como Thomas Edison, em EUA. O cinematógrafo nasce enquanto máquina diretamente ligada a uma tradição de seu século de enxergar o movimento por meio de pontos de vista. Por meio do registro do instante, ser capaz de reconstruir um momento. Tão fugidio é o instante, tão matreira é a memória, dificilmente conseguimos nos dar conta do presente, imbuídos que estamos do passado imediato. Mas eis que se cria uma máquina que é capaz de dar-nos o leve gosto pelo instante, pelo presente. Ainda que um presente que não mais lá está

\section{O relógio}

A filosofia de Bergson centrada num tempo experimentado, vivido, que ele chama de duração, nasce ao final de um século em que diversos aparelhos foram desenvolvidos para tomar posse ou melhor compreender a passagem do tempo. O cinematógrafo encontra-se já ao final de um século bastante produtivo. Um século em que a indústria se desenvolveu, em que as comunicações entre as nações aceleraram, e que necessitava de um meio para poder apresentar toda esta correria. Um dos mais populares aparelhos do século não poderia ser outro: o relógio de bolso. 
Controlando o cotidiano dos indivíduos da urbe (especialmente), o relógio de bolso encontra seu mais alto grau de popularidade na segunda metade do século XIX. Em Alemanha, são importados 12 milhões para uma população de 52 milhões, na década de 1890 . Um crescimento que aponta para dois lados: 1) o relógio enquanto um artigo da moda, que poderia também ser tomado como um artigo de status social; 2) um mecanismo para ordenar a população no sentido de obedecer a uma temporalidade calculável - assim organizando o tempo em direção à produtividade. Esta segunda característica pode ser apontada como uma das causas da intensificação da ansiedade e nervosismo na urbe moderna. A precisão do tempo calculável do relógio leva a uma aceleração das relações sociais, dos encontros, das obrigações, dos eventos, enfim, dos movimentos. O que nos leva a enxergar, a este momento, a distinção de dois modos de encarar o tempo: o tempo calculável do relógio, e a duração vivida pelas pessoas submetidas aos ditames da precisão das máquinas. ${ }^{2}$

Anos antes desta massiva importação de relógios de bolso, se promovia a racionalização do tempo de maneira mais efetiva no desenvolvimento das estradas de ferro e do telégrafo. Por meio do telégrafo se dão as relações comerciais, e econômicas (as casas de ações). Já o caso das estradas de ferro encontra um ponto muito curioso a ser explorado. Em Inglaterra diferentes localidades eram regidas por horários diferentes, o que se mostrava particularmente difícil para as empresas de transportes desenvolverem uma escala de horários de chegada e partida dos trens. Mas uma vez ajustados, não somente os horários dos relógios se relacionaram ao horário da capital. As localidades atendidas pelo serviço ferroviário começam a ser impactadas pela transformação da temporalidade vivida. Certamente não da mesma maneira que a população das metrópoles. O ritmo da urbe moderna passa a se inscrever em diferentes cantos do globo.

Mary Ann Doane lista o relógio de bolso e a padronização dos horários mundiais para facilitação da comunicação por telégrafo e emissão de escalas de chegada e partida dos trens do serviço ferroviário como testamentos da intensificação da racionalização do tempo ao longo da segunda metade do século XIX. Por meio deles o tempo é encarado como uniforme, homogêneo, irreversível e divisível em unidades verificáveis. O tempo vivido, experimentado, aquilo que na filosofia de Bergson é chamado de duração, perde seu espaço em meio à modernidade para que o tempo seja pensado de maneira exata, precisa. Abandonando a ideia

\footnotetext{
2 "Time was indeed felt - as a weight, as a source of anxiety, and as an acutely pressing problem of representation. Modernity was perceived as a temporal demand. Toward the end of the nineteenth century there was a rapid diffusion of pocket watches in the general population. The German historian Karl Lamprecht noted the importation of 12 million watches for a German population of about 52 million in the 1890s" (DOANE, 2002, p. 4).
} 
de um tempo vivido, o tempo deve ser algo a ser visto. Que se possa ter em mãos. O relógio exerce um poder muito grande sobre a imaginação da modernidade, neste sentido. Ele se torna a representação visual do tempo. O mecanismo detentor do tempo. O meio pelo qual o tempo, esta coisa fugidia, é domada por meio de um jogo de ponteiros apontando para linhas e números. ${ }^{3}$

A representação visual do tempo levará a modernidade ao desenvolvimento do cinema. Por meio desta técnica é possível apreender o presente instantaneamente e arquivar a presença. Um desejo contraditório, escreve Doane, uma vez que o que é arquivado torna-se passado. Com o relógio não é possível arquivar o presente. O relógio nos fornece apenas a imagem de um presente imediato. O instante em que o ponteiro habita uma das casas. Tal como acontece na filosofia de Zenão, o relógio nos fornece uma figuração de um tempo divisível ao infinito. Mais que isso, um tempo abstrato. O tempo sob o ditame do relógio permanece sempre o mesmo. O relógio ignora os diferentes movimentos, os diferentes devires, colocando sob os mesmos termos utilizados por Bergson.

O relógio se encaixa dentro da crítica feita por Bergson ao cinematógrafo. Se o cinematógrafo separa os estados do movimento de forma igualitária, sem distinguir um movimento do outro, o relógio promove semelhante feito por meio da divisão do mesmo evento que ele é capaz de promover. O relógio divide todo e qualquer evento da mesma maneira, de forma sintética, marcando quantitativamente quanto tempo levou para que cada movimento singular acontecesse. Este movimento singular pode ser dividido ao infinito para uma análise mais cuidadosa, da mesma forma que pode ser um meio de calcular a performance de alguém em vistas de melhorar o desempenho de um movimento.

O relógio nos apresenta um meio de encarar o tempo como se nunca fosse mudar, o que coaduna com a sociabilidade de nossa inteligência. "Porque a natureza predestinou o homem para a vida social" (BERGSON, 1974, p. 144), o que quer dizer que estamos voltados para o trabalho em comum. E para a realização deste trabalho comum é necessária a completa estabilidade do sujeito, daí ao momento de nascermos sermos nomeados, dados como invariável - o nome que recebemos atesta que permaneceremos o mesmo, a estabilidade da

\footnotetext{
3 "The wide diffusion of the pocket watch, the worldwide standardization of time to facilitate railroad schedules and communication by telegraph, as well as Taylorism's precise measurement of the time of labor and its extension of Gilbreth's cyclographs all testify to the intensity of the rationalization of time in the late nineteenth and early twentieth centuries. Time becomes uniform, homogeneous, irreversible, and divisible into verifiable units. A pocket watch allows its carrier to be constantly in sight of time; similarly, railroad schedules give time a visible and rationalizable form. Gilbreth's researches most adamantly illustrate that the scientific analysis of time involves an unrelenting search for its representation in visual terms - visual terms that exceed the capacity of the naked eye" (DOANE, 2002, p. 6).
} 
identidade física, é assim que poderemos servir a esta vida social na seguridade de uma identidade imutável (nosso nome permanece conosco como sinal de identificação até o momento que morremos). A variabilidade de nossas mudanças será atestada por meio de estados, a aposição de predicados ao sujeito. O relógio é um auxílio nesta vida social desenvolvida sobre as estabilidades. Aponta para a permanência das coisas. Para a semelhança dos eventos. Porque o relógio coloca a todos os eventos em paridade.

Mary Ann Doane já aponta em seu texto, The emergence of cinematic time, o aprofundamento do tratamento quantitativo do tempo. Esta é uma leitura central na argumentação de Bergson. Ele enxerga este procedimento do tempo sendo confundido com espaço e tratado quantitativamente como datando desde os antigos. Sua crítica à filosofia de Zenão surge já em seu primeiro livro em que apresenta a filosofia da duração, Ensaio sobre os dados imediatos da consciência. Mas Bergson em raras ocasiões se volta para uma crítica aos mecanismos da modernidade que popularizam este modo de encarar o tempo, a não ser quando trata o cinematógrafo, em 1907. Sua maior preocupação são as ciências que insistem na leitura do tempo enquanto quantidade. E é este o caminho que a modernidade escolhe traçar.

O relógio é o mecanismo que demonstra a precisão dos serviços e do gasto de esforços que a sociedade moderna está disposta a encarar. A precisão do relógio é a precisão das relações humanas, o trabalho torna-se mais preciso. O relógio é utilizado buscando a eficiência do trabalho. No reino da duração, do tempo vivido, poderíamos dizer o que Mary Ann Doane apresenta desde suas primeiras páginas: a criação da ansiedade. O relógio fornece uma tomada de vistas de fora do sujeito, permitindo que tenhamos acesso apenas a diferentes estados de seu movimento. São estes estados que podem ser aperfeiçoados no trabalho sob as vistas do tempo quantitativo do relógio.

\section{O instante}

A ideia por trás do relógio e do cinematógrafo é muito semelhante. Trata-se de atribuir estados ao movimento, demonstrando a precisão de seu alcance. Com o relógio, esta precisão pode ser aumentada por meio da atribuição de novas unidades de medida (os segundos, os milésimos de segundo). Já com o cinematógrafo a sua precisão pode ser aumentada por meio do aumento de quadros capturados ao longo do movimento (16 quadros por segundo, 24, 29...). Mas estaríamos desta forma a mantermo-nos na mesma querela em que já se havia encontrado Zenão, na antiguidade. Se a flecha deve ocupar sempre o espaço correspondente à 
sua extensão, entre o ponto A e o ponto B de seu movimento podemos atribuir um ponto $\mathrm{C}$, e entre $\mathrm{A}$ e $\mathrm{C}$ um ponto $\mathrm{D}$, assim sucedendo ao infinito.

Mas existe outra forma de interpretar este modo que a modernidade encontrou para tratar o movimento. Seria o que Bergson chama, em Matéria e memória, de percepção puradesprovida do contato com a memória em fluxo, encontro com diversos instantâneos, o presente seria instantâneo; o papel da memória seria então o de ligar estes instantâneos entre si, criando a imagem do mundo, mas por meio destas vistas instantâneas não damos conta da mudança ${ }^{4}$. Apenas atribuímos a distinção entre estados. Mais que isso: interpretar o presente como uma sequência de instantâneos nos leva a dizer que o mundo não dura. E assim como já encontrávamos em Zenão, não existe tempo. "O universo dura” (BERGSON, 2005, p. 12), escreve Bergson em $A$ evolução criadora, já estabelecendo que a duração extrapola a consciência, e se encontra em tudo.

Tratar o presente como uma sequência de instantâneos faz com que permaneçamos na querela do tempo quantitativo. Do tempo que pode ser divisível. Os instantâneos são momentos, estados do móvel ao longo de sua trajetória tomados por nossa inteligência de modo a realizar uma recomposição artificial. Esta recomposição tem um sentido prático, de tentativa de compreensão do movimento. A duração que escorre em fluxo é transformada em algo de palpável, de objetivo. Torna-se matéria para a linguagem e para o cálculo. Ambos atuam de modo objetivo sobre a duração, recortando estados da duração e demonstrando um equivalente material na exterioridade. ${ }^{5}$

O que a percepção pura compreendida como a captação de uma sequência de instantâneos perde é a própria duração. O que significa dizer que é acreditar que nossa visão das coisas seria antes uma coisa do que parte de um sujeito que observa. Mais que isso, a realidade vista como uma sequência de instantâneos deixa escapar a própria essência do movimento: a mudança. Por mais precisão que se busque no trato do movimento, encará-lo enquanto uma sequência de instantâneos é perder algo de muito valioso. A mudança se inscreve não somente nos diferentes estados capturados nos diferentes instantes, mas também

\footnotetext{
4 "Esta é a teoria simplificada, esquemática, que havíamos anunciado da percepção exterior. Seria a teoria da percepção pura. Se a tomássemos por definitiva, o papel de nossa consciência, na percepção, se limitaria a ligar pelo fio contínuo da memória uma série ininterrupta de visões instantâneas, que fariam parte antes das coisas do que de nós" (BERGSON, 1999, p. 68).

5 "Para se chegar a ver no movimento uma série de posições basta um passo; a duração do movimento se decomporá então em 'momentos' correspondentes a cada uma das posições. Mas os momentos do tempo e as posições do móvel são apenas instantâneos tomados por nosso entendimento na continuidade do movimento e da duração. Com essas visões justapostas tem-se um sucedâneo prático do tempo e do movimento que serve às exigências da linguagem e que se espera que sirva às do cálculo; mas nada mais se tem do que uma recomposição artificial. O tempo e o movimento são outra coisa” (BERGSON, 1974, p. 110).
} 
nos momentos perdidos entre os instantes registrados. O que leva Bergson a compreender que o movimento não é uma sequência de instantâneos, e sim um salto. Neste salto, temos o absoluto. A simplicidade do movimento tal como compreendemos quando realizamos qualquer esforço com nossos braços. É a partir do momento em que nos colocamos externamente ao movimento, que estabelecemos perspectivas e colocamos este movimento em relação a outra coisa, que passamos a encará-lo enquanto diferentes estados, diferentes instantes.

Estas colocações levam Bergson até seu encontro com o cinematógrafo, mais uma vez. Se o aparelho cinematográfico atua ao registrar diferentes instantâneos da realidade e depois projetá-los para um público, criando assim a ilusão de movimento, este mesmo filme poderia ser exibido 10, ou 100 vezes mais rápido que nada se alteraria. As imagens captadas pela câmera permaneceriam as mesmas. $\mathrm{O}$ que nos leva a enxergar o cinematógrafo como fazendo parte deste grupo do século XIX que trata o movimento e o tempo enquanto espaço. O tempo enquanto passível de ser calculável, divisível. O que poderíamos considerar é uma parte de nossa frase neste parágrafo: o público do cinematógrafo. Apesar da ilusão, enxergamos o filme como sendo movimento e dizemos que as pessoas estão a se mover. Mais que isso, dizemos que elas têm vida! A este ponto, o cinematógrafo encontra-se num meio termo entre o tempo quantitativo e a duração.

\section{O tempo e a duração}

O cinematógrafo é máquina que desenvolve sua ilusão de movimento a partir da premissa de que o tempo pode ser dividido em diferentes partes iguais e recomposto. Esta é a leitura que Bergson realiza do aparelho, que se assemelha à crítica que ele fez às ciências físicas. Por ora, deixemos esta segunda crítica de lado para focarmo-nos na primeira. Encontramos logo aos primeiros anos da arte do filme duas invenções que podem ser contrapostas. De um lado temos o cinematógrafo, criado pelos irmãos Lumière em França. Para realizar seu trabalho de registrar o movimento, o Cinematógrafo Lumière fotografa 16 instantâneos por segundo. Alguns anos antes dos Lumière, Thomas Edison inventou o Kinetoscope, que captava alguns quadros a mais que a invenção dos irmãos franceses. Pela praticidade da máquina, o Cinematógrafo Lumière conquistou o mundo, mas no meio deste percurso sofreu algumas modificações. Uma delas, captar 24 instantâneos por segundo. A ideia por trás deste aumento no número de quadros para o filme é o melhoramento da qualidade da imagem. Numa interpretação bergsoniana, trata-se de um retorno à filosofia de Zenão. A tentativa ao infinito de encarar o movimento como uma sequência de estados, transformando o tempo em extensão. 
Mary Ann Doane, em The emergence of cinematic time, recorda um filme de vanguarda realizado nos anos 1970, tomando os quadros de um filme dos próprios irmãos Lumière. Demolition of a wall (1973), de Bill Brand, toma seis quadros de um filme de 1896 dos irmãos inventores do cinematógrafo que tinha como tema a demolição de um muro. Brand recorta o começo e o final do filme dos Lumière, ficando apenas com os seis quadros correspondentes à queda do muro. Com estes seis quadros ele realiza 720 diferentes organizações. O movimento de um filme não precisa ser contínuo, atesta Brand com sua peça. Para Doane, Brand abraça o lado ilusionista do cinema e o deixa claro ao espectador. ${ }^{6}$ Por meio deste experimento vanguardista, Brand deixa claro o lado do cinematógrafo de tomar o tempo enquanto extensão e buscar reconstitui-lo. Mas neste caso, a sequência do evento original é corrompida, e o muro nem sempre faz seu caminho em direção ao chão.

A ilusão do movimento pelo cinematógrafo segue algumas ordenações, como bem aponta Doane. Os instantâneos são fotografados numa sequência e nesta mesma sequência devem eles ser exibidos para uma plateia. Da mesma maneira, a velocidade com que foi registrado o movimento original deve ser respeitada - excetuando-se os casos de uso de truques como câmera lenta e aceleração das imagens, por exemplo. O que faz com que o cinematógrafo lide com este tempo quantitativo, respeitando o aspecto máquina do dispositivo. A busca pela reconstrução do móvel a partir do imóvel. Uma tarefa, como colocamos, que não é exclusiva do cinematógrafo.

Em artigo publicado anos antes do lançamento de A evolução criadora, Bergson delineia o caminho para a intuição enquanto método. $\mathrm{O}$ artigo em questão é Introdução à metafísica, e nele Bergson demonstra a importância da coincidência com o objeto no processo de intuição. Esta coincidência é uma referência ao encontro entre o $e u$, consciência duradoura, e o outro. Encontramos algo muito semelhante a esta coincidência em outro texto escolhido para integrar a coletânea $O$ pensamento e o movente, a primeira parte da introdução. "O filósofo [...] é obrigado a constatar que os estados do mundo material são contemporâneos da história de nossa consciência”, (BERGSON, 1974, p. 112) escreve ele. Então o tempo quantitativo do filme de alguma maneira consegue participar da duração.

O que nos faz retornar à afirmação que Bergson já colocava anteriormente: um filme pode ser projetado a qualquer velocidade que nada será modificado. Mas não é assim que acontece quando conjecturamos o filme enquanto arte. $\mathrm{O}$ efeito do acelerar das imagens num filme corrompe o desenrolar original da duração daquilo que fora retratado, mas no filme ele passa a obedecer a outra ordem. Uma temporalidade diversa que já não é mais puramente aquela quantitativa. Exatamente

\footnotetext{
6 "The reconstitution of a 'naturalized' movement is a laborious process subject to certain standards for the reconstruction of time. The ease and obviousness of cinematic movement are deceptive. Much recent avantgarde work in film and, now, digital media no longer takes this reconstitution for granted but instead woks to defamiliarize this motion and time, in short, to bare the device. Bill Brand's Demolition of a Wall, in the manner of the structural/materialist films of the 1970s, activates the frame as a minimal unit. Brand takes six frames from Lumière's Démolition d'un mur and organizes them successively in each of the 720 permutations possible in their ordering. The result is a series of jerky and disorienting movements" (DOANE, 2002, p. 213).
} 
porque o que é registrado em filme participa, em algum nível, da duração real. Bergson não se dedica a ir tão longe em seus estudos a respeito do cinematógrafo, o qual utiliza apenas a título de analogia. Por isso aponta que a velocidade do filme é determinada a se desenrolar de acordo com a duração de nossa vida interior. "O filme que se desenrola está, pois, provavelmente relacionado à consciência que dura e que lhe regula o movimento" (Idem, p. 113). Não sabemos se esta é uma referência ao espectador ou ao cineasta, ou a ambos.

É curiosa a sequência deste parágrafo. O comentário de Bergson a respeito do cinematógrafo se interrompe abruptamente na frase citada no parágrafo anterior. Em seguida ele relembra sua afirmação a respeito do esperar a dissolução do açúcar na água, uma imagem que ele já havia criado em outras oportunidades, notadamente em $A$ evolução criadora. $\mathrm{O}$ ato de esperar que o açúcar se dissolva na água demonstra para Bergson um aspecto significativo de sua peleja em direção à duração. Mostrar que, diferente do tempo quantitativo, a duração não é uma abstração. É tão direta quanto o é esperar o açúcar dissolver-se na água. O casamento do inorgânico com o orgânico cria "aspectos tão novos, tão originais, tão imprevisíveis quanto nossos estados de consciência" (Idem). Curioso que o cinematógrafo seja capaz de criar filmes imprevisíveis e originais quanto nossos estados de consciência. Talvez por este aspecto ainda hoje plateias do mundo todo abracem as imagens em movimento registradas a partir de instantâneos. É a competência do cinematógrafo, ou da câmera de filmar, de registrar o presente em todas as surpresas que ele tem a oferecer. Abrindo a lente para a liberdade do porvir.

É este aspecto que Mary Ann Doane encontra nos filmes dos primeiros anos. Nos filmes realizados na época em que Bergson (e o mundo) começava a conhecer o cinematógrafo. O que ficou conhecido posteriormente como primeiro cinema. Os estudos sobre a arte do filme por muitas décadas ecoaram a fala de Bergson, rejeitando o primeiro cinema. Alguns estudiosos resolveram dar uma nova chance a estes filmes. Descobriram que estes filmes não são tão mecânicos quanto se tomava. Seja os filmes dos Lumière, com uma tendência mais próxima do real, seja os filmes de Méliès, com uma tendência mais próxima ao extraordinário. Nesta competência do cinema de registrar os acontecimentos de modo tão diversos - o real e o fantástico - Doane aponta para as diferentes formas de lidar com o tempo no cinema. Mas, desta vez, enxergando o quão cara é para ambos a liberdade do momento presente. O cinematógrafo, sendo máquina criada para o humano tomar posse do presente, leva-o a enxergar toda a diversidade com que os eventos se desenrolam.

Esta diversidade, ou a variabilidade do devir (para seguir o vocabulário de Bergson), é apontada por Mary Ann Doane num filme dos Lumière intitulado Barque sortant du port (Barco saindo do porto, 1897). Neste filme temos o estilo característico do primeiro cinema: a câmera fixa, o campo aberto e o evento levando todo o tempo do filme para acontecer (todos os 50 segundos de filme possível de inserir no cinematógrafo). A aventura de um grupo de pessoas que resolve adentrar o mar com um barco a remo. O tempo do filme, permitindo o desenrolar do evento, nos oferece o contato 
com o aleatório, com a surpresa do inesperado. O filme deixa de fazer parte puramente do tempo quantitativo, para fazer parte da duração. O evento é marcado pela expectativa de que os barqueiros venham a completar sua passagem, mas o inesperado acontecimento natural, a onda, continua os empurrando de volta para o porto. O filme acompanha o evento até que o inesperado se apresente, mostrando assim sua competência em mostrar o devir variável. Sua participação da duração não acontece somente por meio de seu contato com a duração do espectador ou do cineasta, o filme é capaz de se conectar com a duração do evento do qual ela participa enquanto testemunha - neste caso, a tentativa dos barqueiros de deixar o porto. ${ }^{7}$

No caso de Méliès, sua relação com o acaso e a liberdade do presente é diferente. Porque apesar da câmera se manter gravando por longos momentos, como podemos testemunhar no famoso Viagem à Lua (Le Voyage dans l alune, 1902), seus filmes são direcionados para o fantástico, para o extraordinário, e o tempo deles caminha em sentido semelhante. Mary Ann Doane escreve que, apesar do forte controle tido pelo autor, os filmes de Méliès caminham sempre em direção a uma perda de controle. O fantástico ganha os contornos da liberdade do presente. A expectativa é constantemente corrompida por eventos cuidadosamente orquestrados. A câmera não muda seu posicionamento ao longo da trama, mas por meio de uma trucagem por ela possibilitada, o espetáculo filme apresenta ao público uma possibilidade de encontro com o acaso completamente diferente. Uma metamorfose diversa daquela que poderia ser encontrada na natureza. A variabilidade do devir encontra a imaginação humana e suas fantasias. ${ }^{8}$

\section{O relógio, o cinematógrafo e uma conclusão}

O cinematógrafo é desenvolvido com o intuito de registrar o instante, arquivar o presente. Um desejo particular do século XIX, que já havia entregue ao mundo a máquina fotográfica, um parente próximo da máquina de filmar. Bergson é perspicaz ao afirmar que o cinematógrafo atua por meio de uma ilusão. O movimento é recomposto por meio de instantâneos, ou para utilizar o vocabulário do próprio filósofo, o movimento é recomposto por meio de estados. Neste sentido, o cinematógrafo é máquina, obedece aos ditames do tempo quantitativo, de um sistema perfeitamente calculável. Mas que curioso é notar que esta

\footnotetext{
7 "As the camera holds on the departing boat in Lumière's A Boat Leaving Harbor (Barque sortant du port, 1897), the sheer duration of filmic time allows for the random event, the surprise of the unexpected wave. This representation of time carries with it both the frisson and the threat/anxiety of the unexpected and is culturally tolerable only for a very brief period at the turn of the century. In the classical cinema, the cut aborts the problem of an excess of the random, of chance in time" (DOANE, 2002, p. 137).

8 "Méliès' relation to contingency and the random event is somewhat different. In spite of the extensive control and mastery exhibited in Méliès' films, they dramatize - often quite explicitly - the effect of a loss of control. The inexplicable appearances and disappearances of bodies and objects, the transformation of entities into each other, the independent action of limbs, and unexpected exaggerations of scale all pay homage to contingency despite the fact that they are carefully orchestrated." (DOANE, 2002, p. 137)
} 
máquina tem outro lado! A máquina mostra-se um meio para a arte do filme, esta novidade que nos foi ofertada por um século XIX em seus últimos suspiros.

A arte do filme não funciona dentro dos ditames do tempo quantitativo. Ela obedece a um fluxo. O presente não aparece simplesmente como instante. $\mathrm{O}$ instantâneo registrado pela máquina de filmar surge unido ao instantâneo anterior. A imagem, por assim dizer, teria uma memória, e cria uma expectativa sobre o porvir. E o que virá pode se desdobrar de múltiplas maneiras. Lumière e Méliès são provas disso. Algo de completamente extraordinário pode se desvelar perante as lentes do cinematógrafo. E o acaso e o inesperado são testemunhados pelos espectadores da projeção. Não seria um devir geral que encontramos na arte do filme. O movimento, assim, não se encontra somente na máquina de projetar.

Mary Ann Doane escreve que o cinema elimina o relógio científico. Não é possível para a arte do filme se manter tendo como referencial o tempo quantitativo. $\mathrm{O}$ cinema tinha, assim, que mostrar que a experiência do tempo em seu universo próprio é um tanto próxima desta nossa. O tempo tomado enquanto duração, um termo que Doane toma emprestado de Bergson. A arte do filme se separa das marcações precisas do tempo científico, que o relógio representa tão bem. Abre-se para o devir em infinitas possibilidades. ${ }^{9}$

O relógio, por outro lado, permanece imerso no pensamento do tempo quantitativo próprio ao século XIX. O relógio se inscreve na tradição de recortar o tempo em partes iguais, em reconstruir a experiência por meio de estados. $\mathrm{O}$ cinematógrafo, neste sentido, tem forte proximidade com o relógio. Mas para se afirmar enquanto a arte do filme, se viu obrigado a distanciar-se do tempo quantitativo, como bem coloca Doane. O relógio, por outro lado, ignora a duração e participa ativamente de nosso cotidiano, demarcando nossas experiências como se fossem elas todas iguais. A distinção se faz pelos estados que ele recorta igualmente. No universo do relógio, não há lugar para a duração, diferente do que acontece com o cinematógrafo.

O instante aparece nestas duas invenções do século XIX de modo diverso. Em ambos os casos é inicialmente visto que o presente é composto por instantes. Mas enquanto o relógio apenas distingue estes instantes por meio de seu sistema perfeitamente calculável, o cinematógrafo possui a possibilidade de abandonar o tempo e aproximar-se da duração (experiência).

\footnotetext{
9 "The cinema, on the other hand, had to eliminate the scientific clock, the clock as a record of referential time. Instead the cinema, as the production of a generalized experience of time, of duration, had to ensure that its temporality was nonspecific, nonidentifiable, indeterminable" (DOANE, 2002, p. 214).
} 


\section{REFERÊNCIAS BIBLIOGRÁFICAS}

BERGSON, Henri. O pensamento e o movente, introdução. Trad. Franklin Leopoldo e Silva. In Os pensadores: Henri Bergson, cartas conferências e outros escritos. $1^{\mathrm{a}}$ ed. São Paulo: Abril Cultural, 1974.

. Introdução à metafísica. Trad. Franklin Leopoldo e Silva. In Os pensadores:

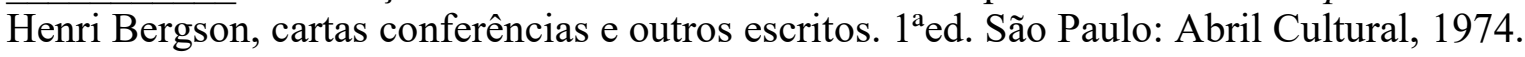
. Matéria e memória. Trad. Paulo Neves. 2aed. São Paulo: Martins Fontes, 1999. Fontes, 2005. . A evolução criadora. Trad. Bento Prado Neto. $1^{\mathrm{a} e d}$. São Paulo: Martins

. Ensaio sobre os dados imediatos da consciência. Trad. João da Silva Gama. 1ed. Lisboa: Edições 70, 1988.

DELEUZE, Gilles. A imagem-movimento. Trad. Stella Senra. s/ed. São Paulo: Brasiliense.

DOANE, Mary Ann. The emergence of cinematic time: modernity, contingency and the archive. $1^{\mathrm{a}} \mathrm{ed}$. Cambridge: Harvard University Press, 2002. 